\title{
South Eastern Histologic Pattern of Lymph Node Biopsies in a Tertiary Hospital in Nigeria
}

\author{
Mbata GC ${ }^{1 *}$, Nweke IG², Egejuru RO², Omejua EG ${ }^{1}$, Nwako OF${ }^{1}$, Chima El ${ }^{1}$ and Oparaocha D $^{3}$ \\ ${ }^{1}$ Department of Internal Medicine, Federal Medical Centre, Owerri, Imo State, Nigeria \\ ${ }^{2}$ Department of Pathology, Federal Medical Centre Owerri, Imo State, Nigeria \\ ${ }^{3}$ Department of Surgery, Federal Medical Centre Owerri, Imo State, Nigeria
}

\begin{abstract}
Background: In patients presenting with lymphadenopathy, evaluation of the biopsy specimen of accessible lymph nodes provides specific information to establish an early diagnosis which is important in the management of these patients.

Method: The study is a four-year (2010-2013) retrospective audit of all histologically diagnosed lymph node biopsies of 141 cases received at the Federal Medical Centre Owerri, Eastern Nigeria.

Results: Nearly one third 46(32.6\%) of the 141 patients had reactive hyperplasia. Tuberculous lymphadenopathy $40(28.3 \%)$ and metastasis $27(19.7 \%)$ were other common causes. Non Hodgkins lymphoma was seen in $17(12 \%)$, while Hodgkins lymphoma was seen in $7(5 \%)$. Other cases seen were onchocerciasis $3(2.1 \%)$ and Rosai - Dorfman's disease $1(0.7 \%)$. Acid-fast bacilli was demonstrated in $12 / 40(30 \%)$ of Tuberculous adenitis. All the patients with TB were screened for HIV and $14 / 40(35 \%)$ of them were HIV positive. Six patients had generalized lymphadenopathy and $4 / 6(66.6 \%)$ of them were HIV positive.

Conclusion: The differential diagnoses of lymphadenopathy are many. Tuberculosis and reactive hyperplasia have remained the predominant causes in our environment; followed by malignancy and lymphoma. Accurate diagnosis and early intervention is the key to good treatment outcome. Definitive histological classification using modern techniques like immunohistochemistry and cytogenetics should be made available in our tertiary hospitals.
\end{abstract}

Keywords: Lymphadenopathy; Reactive hyperplasia; Tuberculosis; Metastasis; Eastern Nigeria

\section{Introduction}

Lymphadenopathy is a common clinical presentation in both medical and surgical clinics worldwide. The causes may be broadly divided into neoplastic and non-neoplastic. The non-neoplastic vary from infective agents, drug reactions, lipid storage disorders, and nonspecific inflammatory conditions [1].

Documented reports have shown that non neoplastic causes predominate with non-specific reactive hyperplasia in the developed countries, while tuberculosis is the main cause in the developing world; especially in Africa where HIV has ravaged the whole continent. HIV apart from directly causing lymphadenopathy also contributes indirectly via several AIDS- defining illnesses [2-8].

A number of diseases are well known to cause lymphadenopathy. Given this numerous causes, it has become necessary to define the diseases presenting with lymph node enlargement in a particular environment. While the pattern of lymphadenopathy in the child is occasionally infective and reactive to a minor stimulus because of the yet developing immune system; the cause in the adulthood has been largely due to metastatic carcinoma [9-13].

Clinical assessment of peripheral lymphadenopathy is easier since they are easily assessable and biopsied 14 . On the other hand, assessment of visceral lymphadenopathy is much more difficult since they require imaging assistance or laparotomy [14]. Biopsy of the peripheral lymph nodes in the upper part of the body (cervical, supraclaviclar, axillary) is often desired as they give better diagnostic yield. The lymph nodes in the lower region (popliteal, inguinal, femoral) are less biopsied because they are characterized by non-specific or chronic inflammatory fibrotic changes $[1,7,14]$.

\section{Objective of the Study}

Data on the spectrum of diseases causing lymphadenopathy in the South-Eastern region are limited. This study therefore aims at investigating the causes of lymphadenopathy and the pattern of lymph node distribution in patients seen at Federal Medical Centre Owerri over a 4- year period. The information obtained from this study will assist the clinician in the clinical practice and also add to the already documented data both in the sub-region and beyond.

\section{Materials and Methods}

All cases of lymph node biopsies received at the Department of Pathology at the Federal Medical Centre Owerri, Nigeria from January 2010 to December 2013 were reviewed. The Centre is a referral centre offering histopathology services to the entire Imo State and other surrounding States in the Eastern Nigeria. Both clinical and demographic data regarding age, sex, anatomical site of nodal biopsy were obtained from request forms and case notes. The relevant slides were retrieved from the archives of the Department of Pathology. All the slides were prepared from paraffin embedded blocks, then routine stain

*Corresponding author: Mbata GC, Department of Internal Medicine, Federal Medical Centre, PMB 1010, Owerri Imo State Nigeria, Tel: 234-803-356-9235 E-mail: mbatag@yahoo.com

Received October 25, 2014; Accepted June 12, 2015; Published June 19, 2015

Citation: Mbata GC, Nweke IG, Egejuru RO, Omejua EG, Nwako OF, et al. (2015) South Eastern Histologic Pattern of Lymph Node Biopsies in a Tertiary Hospital in Nigeria. J AIDS Clin Res 6: 475. doi:10.4172/2155-6113.1000475

Copyright: @ 2015 Mbata GC, et al. This is an open-access article distributed unde the terms of the Creative Commons Attribution License, which permits unrestricted use, distribution, and reproduction in any medium, provided the original author and source are credited. 
done with eosin and haematoxylin. Special stains like Ziehl Neelson stain were used where necessary. Cytogentics, immunohistochemistry and molecular diagnostic technique like lymphocyte receptor genes re- arrangements were not employed as these were not available in our laboratory.

\section{Ethical clearance}

The ethical clearance was obtained from the Ethics Committee of Federal Medical Centre Owerri, Imo State Nigeria.

\section{Data analysis}

Data were analyzed using SPSS version 16 Chicago IL.

\section{Results}

Table 1 shows A total of 141 lymph node biopsies were obtained which constituted $6 \%$ of total biopsies during the 4 -year period of study (January, 2010-December, 2013). Out of the 141 cases 60 were males while 81 were females with male to female ratio of 1:1.3. Mean age was $17.6 \pm 8.5$ while the age range of the patients was 68 years $(2-70)$ years. Table 1 shows the age distribution of the patients and the various conditions with significant $p$ value of $0.000\left(\chi^{2}=43.095\right)$.

Table 2 shows the site, distribution and histological diagnosis of diseases and the frequency of enlargement of the different groups of lymph nodes.

Regional lymphadenopathy was seen in 135(95.7\%) while generalized lymphadenopathy occurred in $6(4.3 \%)$ of the patients; with cervical group of lymph nodes being the most frequently affected 64 (45.4\%), followed by axillary $28(19.9 \%)$ and supraclaviclar $12(8.5 \%)$.

Reactive hyperplasia was the most common condition $46(32.6 \%)$, followed by tuberculosis $40(28.3 \%)$. Metastatic deposits were seen in 27(19.1\%). Non Hodgkins lymphoma was seen in 17(12.1\%) while Hodgkins lymphoma was seen in 7(5\%). Onchocerciasis was seen in $3(2.1 \%)$ and Rosai -Dorfman's syndrome was seen $1(0.7 \%)$.

Table 3 shows histologic diagnosis, sex distribution and sex ratios in patients with lymphadenopathy. Lymphadenopathy was more common in females; with female ratios higher in most of the conditions except non Hodgkins lymphoma where male ratio was higher. Though, we have more female preponderance but the $\mathrm{p}$ value of 0.326 was not significant.

Out of the $40(28.3 \%)$ of patients with TB adenitis; acid fast bacilli (AFB) were demonstrated in $12 / 40(30 \%)$. Voluntary testing and counseling was done for all the patients with TB lymphadenopathy; 14/40 (35\%) were HIV positive. Of the 6 patients who have generalized lymphadenopathy, 4/6(66.6\%) of them were HIV positive.

\section{Discussion}

Palpable peripheral lymph nodes give an important diagnostic

\begin{tabular}{|c|c|c|c|c|c|c|c|c|}
\hline AGE RANGE & TOTAL & REACT. HYPER & TB & METAS & NHL & HL & ROSAI DOF & ONCHO \\
\hline $0-9$ & 31 & $21(67.7)$ & $8(25.8)$ & $2(6.5)$ & - & - & - & - \\
$10-19$ & 21 & $12(57.1)$ & $8(38.1)$ & $1(4.8)$ & - & - & - \\
$20-29$ & 26 & $8(30.8)$ & $8(30.8)$ & $3(11.5)$ & $4(15.4)$ & $2(7.7)$ & - & $1(3.8)$ \\
$30-39$ & 17 & $3(17.6)$ & $5(29.4)$ & $6(35.3)$ & $2(11.8)$ & - & $1(5.9)$ & - \\
$40-49$ & 14 & $1(7.1)$ & $4(28.6)$ & $5(35.7)$ & $2(14.3)$ & $1(7.1)$ & - & $1(7.1)$ \\
$50-59$ & 13 & $1(7.7)$ & $5(38.4)$ & $3(23.1)$ & $3(23.1)$ & $1(7.7)$ & - & - \\
$60-69$ & 16 & - & $2(12.5)$ & $6(35.7)$ & $5(31.3)$ & $2(12.5)$ & - & $1(6.2)$ \\
$\geq 70$ & 3 & - & - & $1(33.3)$ & $1(33.3)$ & $1(33.3)$ & - & - \\
\hline TOTAL & 141 & 46 & 40 & 27 & 17 & 7 & 1 & 3 \\
\hline
\end{tabular}

Mean Age $=17.6 \pm 8.5$ years, Range $=68$ years $(2-70$ years $)$.

$\chi^{2}=43.095 ; p$ value 0.000 (significant).

TB - Tuberculosis; METAS - Metastasis; NHL - Non Hodgkins Lymphoma; HL- Hodgkins Lymphoma; ROSAI DOF - Rosai Dorfman Disease; ONCHO- Onchocerciasis. Table 1: Age Distribution of Patients.

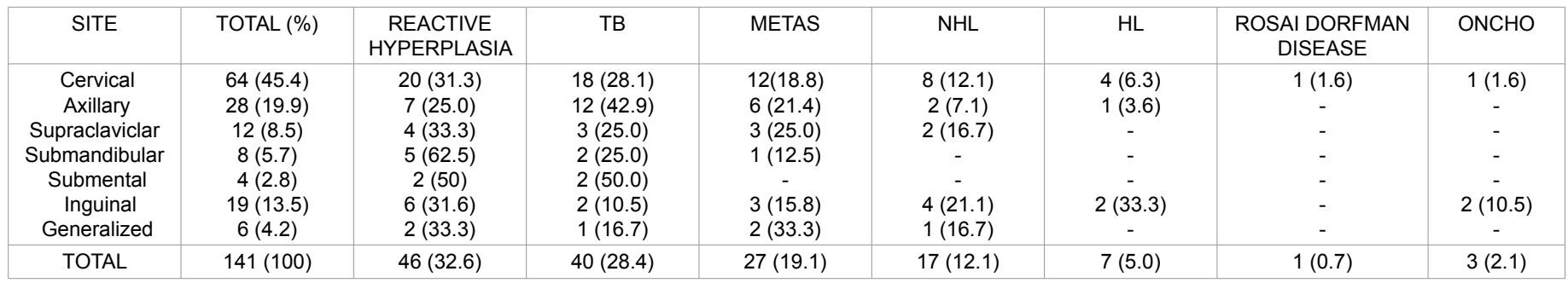

TB - Tuberculosis; METAS -Metastasis; NHL - Non Hodgkins Lymphoma; HL- Hodgkins Lymphoma; ONCHO- Onchocerciasis.

Table 2: Site Distribution and Histologic Diagnosis.

\begin{tabular}{|c|c|c|c|c|}
\hline DIAGNOSIS & NO.OF CASES (\%) & MALES (\%) & FEMALES (\%) & M:F RATIO \\
\hline $\begin{array}{c}\text { Reactive Hyperplasia } \\
\text { Tuberculosis } \\
\text { Metastatic } \\
\text { Non Hodgkins Lymphoma } \\
\text { Hodgkins Lymphoma } \\
\text { Rosai Dorfman Disease } \\
\text { Onchocerciasis }\end{array}$ & $\begin{array}{l}46(32.6) \\
40(28.4) \\
27(19.1) \\
17(12.1) \\
7(5.0) \\
1(0.7) \\
3(2.1)\end{array}$ & $\begin{array}{c}20(14.2) \\
16(11.4) \\
11(7.8) \\
10(7.1) \\
2(1.4) \\
1(0.7) \\
-\end{array}$ & $\begin{array}{c}26(18.4) \\
24(17.0) \\
16(11.3) \\
7(5.0) \\
5(3.6) \\
- \\
3(2.1)\end{array}$ & $\begin{aligned} 1 & : 1.3 \\
1 & : 1.5 \\
1 & : 1.5 \\
1.4 & : 1 \\
1 & : 2.5 \\
& - \\
& -\end{aligned}$ \\
\hline TOTAL & $141(100)$ & $60(42.6)$ & $81(57.4)$ & \\
\hline
\end{tabular}

$\chi^{2}=6.94, \quad p$ value $=0.326$ (not significant).

Table 3:_Histologic Diagnosis, Sex Distribution and Sex Ratios of Patients with Lymphadenopathy. 
clue to the aetiology of the underlying medical or surgical condition. Fine needle aspiration cytology (FNAC) is more commonly used to establish the aetiological diagnosis; but excision biopsy of the lymph node is the gold standard for diagnosis $[2,15,16]$. Except for the few patients on admission, biopsy was done as outpatient procedure with minimal morbidity and no mortality attributed to the procedure, thus supporting the fact that it is a simple and efficient method for confirmation of clinical diagnosis.

In line with most other studies done within and outside Nigeria, cervical nodes were the most frequently biopsied [2-4,6-8]. This was followed by the axillary and supraclaviclar lymph nodes. The finding also showed that the most common aetiologic factors were tuberculosis and reactive hyperplasia. In this study tuberculosis was found to be more common in the submental (50\%) followed by axillary $(42.9 \%)$ and cervical nodes (28\%). Reactive hyperplasia was seen to be more common in the submandibular (62.5\%) and submental (50\%) groups of lymph nodes. The study showed that both conditions were more common in children and young adults and with more female preponderance (Tables 1 and 3 ).

Generally speaking lymphadenopathy is common in the first three decades of life; with reactive lymphadenoathy more common in the early years of life, TB common in the young adult and malignancy seen more in the adult and elderly people $[9,10,12,13]$. This is in line with our finding which is quite significant when we look at the age distribution in table 1 with $\mathrm{p}$ value of 0.000 .

Analysis of lympadenopathy in the clinical practice in the developing nations of the world has shown that infection remains an important cause with TB as the most common aetiology in most areas $[2-6,13,16,18]$. Nonspecific causes (reactive hyperplasia) and upper respiratory tract infections due to bacterial and viral agents are also important cause of lymphadenopathy in the developing world, while malignancy and reactive hyperplasia are more commonly implicated in the developed world $[3,19,20,21]$.

In this study, out of 141 patients nonspecific cause (reactive hyperplasia) was found in 46 (32.6\%) making it the most common aetiologic factor in our study. Tuberculosis which is the most common aetiologic factor in many studies done within our environment was found to be the second aetiologic factor in our study with $40(28.3 \%)$. The percentage of TB lymphadenopathy found here was also smaller than that found in some series $[2-5,7,8]$ with higher prevalence quoted in India, Pakistan and Bangladesh [22,23]. The reason for this lower rate is attributed to the fact that our study included children who have more of reactive hyperplasia while most of the studies done elsewhere were in adult population only. The reason for more common reactive lymphadenopathy in children has been adduced to a reaction to minor stimuli because of the yet developing immune system [12,14]. In the United States of America reactive hyperplasia is more common cause of lymphadenopathy $[3,19]$. The lower prevalence of tuberculosis and earlier detection of malignancies before the onset of nodal metastasis may be the explanation for the prominence of reactive hyperplasia as a more common cause in the western world [14]. Lymph node hyperplasia was also found to be common in studies done in India 24, South Africa 16 and Zimbabwe [15]. The hyperplasia appears to be a consequence of variety of pathological processes; an important factor being that of HIV infection [24]. The trend of changes in primary HIV lymphadenopathy has been reported to range from mild follicular hyperplasia through diffuse follicular hyperplasia to "burnt out lymph node" [24].

In our study, metastasis comprised of 27(19.1\%) of the cause of lymphadenopathy. This is similar to the finding in Kano [14] and some other Nigerian cities but significantly higher than values quoted for other African countries like Zimbabwe [15] and Ethiopia [6]. In the United States metastasis was found in $29 \%$ of lymph node enlargement $[14,19]$. The most common cause of metastasis in our study was breast cancer affecting mostly the axillary groups of lymph nodes. This finding is also in agreement with other Nigerian studies [14,25].

Lymphomas were the most common cause of malignancies in our study accounting for $24(17 \%)$ of lymphadenopathy. This is lower than the findings in other Nigerian studies with $23.6 \%$ in Kano [14], $23.8 \%$ in Ife [26], 28.2\% in Ilorin [2] and $28.2 \%$ in Jos [4]. In our study non Hodgkins is higher $17(12 \%)$ than Hodgkins $7(5 \%)$. Most other Nigerian studies also gave a higher preponderance of non Hodgkins lymphoma $[2,27,28,29]$. Also in the western world non Hodgkins lymphoma is reported to be three to four times more common than Hodgkins [30,31].

Onchocerciasis is most common in the tropical and Sub Saharan regions of Africa. The microfilarial infection is a known cause of mild to moderate lymphadenopathy. In our study $3(2.1 \%)$ of the causes of lymphadenopathy was due to onchocerciasis. The study in Benin City, Nigeria showed $0.9 \%$ [13]. It was also more common in the young adult females [13]. Our study also gave similar results with all our three patients being females and also predominantly affecting the inguinal lymph nodes.

The study is a retrospective one with its attendant limitation in that microbiological aspect of the study was not done. This would have certainly revealed some of the aetiologic agents.

\section{Conclusion}

In conclusion, the pattern of lymph node histology in the developing world has remained predominantly due to tuberculosis and lymphoid hyperplasia. Malignancy and lymphomas are other common causes. Our study supports these findings. Again, routine staining with haematoxylin and eosin and special staining with Ziehl-Neelson stain have remained the means of diagnosis in these areas over a period of time. There is therefore need to update our pathology laboratories with modern diagnostic facilities such as immunohistochemistry, cytogenetics and molecular diagnostic techniques like lymphocyte receptor gene rearrangements to increase their diagnostic efficiency.

\section{Ethical Approval}

Obtained from the Ethical Committee of the Federal Medical Centre Owerri, Imo State.

\section{References}

1. Rosai J (2011) Lymph nodes. 2011 In: Ackerman's surgical pathology. Mosby, St Louis 1771-1899.

2. Adeniji KA, Anjorin AS (2000) Peripheral lymphadenopathy in Nigeria. African J Med Sci 29: 233-237.

3. Longo DL, Fauci A, Kasper D, Hauser S (2012) Harrisons online (18 $8^{\text {th }}$ edn). The Mc Graw-Hill companies, New York, NY.

4. Obafunwa JO, Olomu IN, Onyia NJ (1992) Primary peripheral lymphadenopathy in Jos, Nigeria. West Afr J Med 11: 25-28.

5. Pindiga UH, Dogo D, Yawe T (1999) Histopathology of primary periphera lymphadenopathy in Northeastern Nigeria. Nigerian Journal of Surgical Research: 68-71.

6. Ferrer R (1998) Lymphadenopathy: differential diagnosis and evaluation. Am Fam Physician 58: 1313-1320.

7. Cotran RS, Kumar V, Collins T (1999) Acquired immune deficiency Syndrome In Robbins pathologic basis of diseases. Saundrs, Philiadephia : 247-250. 
Citation: Mbata GC, Nweke IG, Egejuru RO, Omejua EG, Nwako OF, et al. (2015) South Eastern Histologic Pattern of Lymph Node Biopsies in a Tertiary Hospital in Nigeria. J AIDS Clin Res 6: 475. doi:10.4172/2155-6113.1000475

Page 4 of 4

8. Lake AM, Oski FA (1978) Peripheral lymphadenopathy in childhood. Ten - year experience with excisional biopsy. Am J Dis Child 132: 357-359.

9. Okolo SN, Nwana EJ, Mohammed AZ (2003) Histopathologic diagnosis of lymphadenopathy in Children in Jos, Nigeria. Postgraduate Medical Journa 10:165-167.

10. Narang $P$, Narang R, Narang $P$, Mendiratta DK, Sharma SM, et al. (2005) Prevalence of tuberculous lympadenitis in children in Wardha district, India. Int. J Tuberc Lung Dis 9: 188-194.

11. Adelusola KA, Oyelami AO, Odesanmi WO, Adeodu OO (1996) Lymphadenopathy in Nigerian children. West African J Med 15: 97-100.

12. Olu - Eddo AN, Ohanaka CE (2006) Peripheral lymphadenopathy in Nigerian adults. Journal of Pak Med Association 56: 405-408.

13. Ochicha O, Edino ST, Mohammed AZ, Umar AB, Atanda AT (2007) Pathology of peripheral lymph node biopsies in Kano, Northern Nigeria. Ann Afr Med 6 : 104-108.

14. Sibanda EN, Stanczuk G (1993) Lymph node pathology in Zimbabwe: A review of 2194 specimens. Q J Med 86: 811-817.

15. Moore SW, Schneider JW, Schaaf HS (2003) Diagnostic aspects of cervical lymphadenopathy in children in the developing world: a study of 1,877 surgical specimens. Paediatric Surg Int 19: 240-244.

16. Thomas JO, Ladipo JK, Yawe T (1995) Histopathology of lymphadenopathy in a tropical country. East African Med J 72: 703-705.

17. Bem C, Patil PS, Bharucha H, Namaambo K, Luo N (1996) Importance human immune deficiency virus-associated lymphadenopathy and Tuberculous adenitis in patients undergoing lymph node biopsy in Zimbabwe. $\mathrm{Br} \mathrm{J}$ of Surg 83:75-78.

18. Lee YT, Terry R Luke RJ (1982) Biopsy of peripheral lymph node. Am Surg 48: $536-539$

19. Freidig EE, Mc Clue SP, Wilson WR, Banks PM, Washington JA(1986) Clinical- histologic- Microbilogic analysis of 419 lymph node biopsy specimens. Rev Infect Disease 8: 322-328.

20. Sriwatanawongsa V, Cardoso R, chang P (1985)Incidence of malignancy in peripheral lymph node biopsy. Am Surg 51: 587-590.

21. Hemalath K, Grace K, kulkarni G, Job CL (1972) Tuberculous adenitis in SouthIndia - a histopathologic and bacteriologic study. Tubercule 53: 215-220.

22. Chhabra S, Mohan H, Bal A (2005) A retrospective histological evaluation of non neoplastic superficial lymphadenopathy. The Internet Journal of Internal Medicine 6.

23. Mohan A, Reddy MK, Phaneendra BV, Chandra A (2007) Aetiology of peripheral lymphadenopathy in adults: Analysis of 1724 cases seen at a tertiary care teaching hospital in Southern India. Natl Med J India 20: 78-80.

24. Obiorah CC, Ray-Offor E (2013)Pathology of lymphoreticular diseases in Nigeria: A Multi-Centre Study. Pioneer Medical Journal 3: 33-39.

25. Udani PM, Maddocks I (1981) Tuberculosis. In Jellife DB. Diseases of children in subtropics and tropics. Arnold, London 301-317.

26. Pindiga HU, Ahmed SG (2002) Histological types of lymphoma in northeastern Nigeria. Sahel Medical Journal (Nigeria) 5: 43-46.

27. Adedeji MO (1989) Malignant lymphoma in Benin City, Nigeria. East African Med J 66: 134-140.

28. Obafunwa JO, Akinsete I (1992) Malignant lymphoma in Jos, Nigeria: a tenyear study. Central African J of Med 38: 17-25

29. Hartge P, Devessa SS, Fraumeni JF (1994) Hodgkin's and non-Hodgkin's lymphomas. Cancer Surv 19-20: 423-453.

30. Groves FD, Linet MS, Travis LB, Devessa SS (2000) Cancer Surveillance Series: Non-Hodgkin's Lymphoma Incidence by Histologic Subtype in the United States From 1978 Through 1995. J Natl Cancer inst 92: 1240-1251.

31. Chee YC (1982) Tuberculous lymphadenitis in Singapore. Ann Acad. Med Singapore 11: 587-592. 